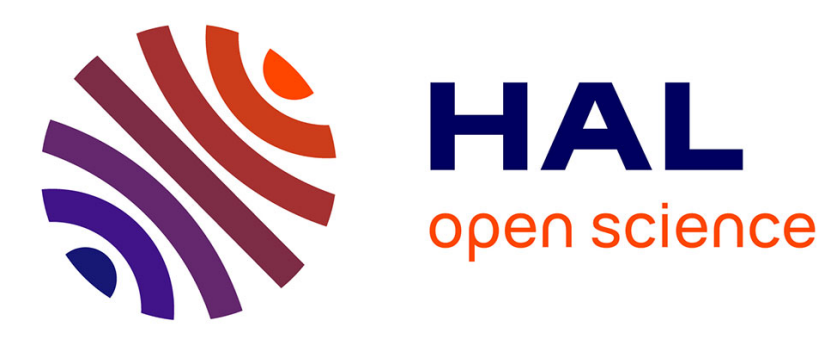

\title{
Scalable normally-off MIS-HEMT using Fluorine implantation below the channel
}

Saleem Hamady, Frédéric Morancho, Bilal Beydoun, Patrick Austin, Mathieu

Gavelle

\section{- To cite this version:}

Saleem Hamady, Frédéric Morancho, Bilal Beydoun, Patrick Austin, Mathieu Gavelle. Scalable normally-off MIS-HEMT using Fluorine implantation below the channel. SPEEDAM 2014, Jun 2014, Ischia, Italy. hal-01054228

\section{HAL Id: hal-01054228 \\ https://hal.science/hal-01054228}

Submitted on 5 Aug 2014

HAL is a multi-disciplinary open access archive for the deposit and dissemination of scientific research documents, whether they are published or not. The documents may come from teaching and research institutions in France or abroad, or from public or private research centers.
L'archive ouverte pluridisciplinaire HAL, est destinée au dépôt et à la diffusion de documents scientifiques de niveau recherche, publiés ou non, émanant des établissements d'enseignement et de recherche français ou étrangers, des laboratoires publics ou privés. 


\title{
Scalable normally-off MIS-HEMT using Fluorine implantation below the channel
}

\author{
Saleem Hamady ${ }^{1,2,4}$, Frédéric Morancho ${ }^{1,3}$, Bilal Beydoun ${ }^{4}$, Patrick Austin ${ }^{1,3}$, Mathieu Gavelle ${ }^{1,2}$ \\ ${ }^{1}$ CNRS, LAAS, 7 avenue du Colonel Roche, F-31400 Toulouse, France \\ ${ }^{2}$ Univ de Toulouse, LAAS, F-31400 Toulouse, France \\ ${ }^{3}$ Univ de Toulouse, UPS, LAAS, F-31400 Toulouse, France \\ ${ }^{4}$ GET/LPE, Lebanese University, Hadath campus, Beirut, Lebanon \\ E-Mail: shamady@laas.fr, morancho@laas.fr, bilbey@ul.edu.lb, austin@laas.fr, mathieugavelle@yahoo.fr
}

\begin{abstract}
A new normally-off Metal-InsulatorSemiconductor High-Electron-Mobility-Transistor (MIS-HEMT) is proposed. The design is based on the implantation of fluorine ions in the GaN layer below the gate electrode under the AlGaN/GaN interface. Sensitivity analyses are carried out, showing the effects of the fluorine concentration and the thickness of the insulator on the threshold voltage. The limitations and scalability of this technique are pointed out.
\end{abstract}

Keywords- Metal Insulator Semiconductor High Electron Mobility Transistor (MIS-HEMT); Fluorine implantation below the channel; TCAD simulation; normally-off; wide bandgap devices

\section{INTRODUCTION}

AlGaN/GaN HEMTs are very promising candidates for high frequency applications with high power and low noise, such as microwave and millimeter wave communications, imaging and radars [1]. While switching applications strongly demand normally-off operation [2], conventional HEMTs attain a channel populated with electrons at zero gate voltage making them normally-on. For the sake of achieving normallyoff HEMTs, several structures have been proposed such as recessed gate structures [3], fluorine ion treatment [4], pn junction gate structures [5], thin AlGaN barrier [6], AlN/GaN structure [7] and InGaN cap layer [8]. However, with the above mentioned structures having a low threshold voltage, noise blocking would be a problem. To prevent misoperation due to noise, the threshold voltage should be above $3 \mathrm{~V}$ [9]. Moreover, the gate leakage occurring during on-state operation strongly limits the device's performance, especially when high threshold voltage and high current densities are required.

For the aim of reaching high threshold voltage with no gate leakage, an insulating layer is introduced between the gate metal and the semiconductor material. The insulating material, also known as the gate dielectric, varies from $\mathrm{SiO}_{2}$ [10], $\mathrm{SiN}$ [11], $\mathrm{HfO}_{2}$ [12] to $\mathrm{Al}_{2} \mathrm{O}_{3}$ [13]. These devices are known as Metal-Insulator-Semiconductor HEMTs (MIS-HEMTs). Most of the normally-off MIS-HEMTs use one [10] [12] [14], or a combination [15] of the above mentioned techniques. The effectiveness of the agent used to obtain normally-off, whether it is recessing the gate, introducing a cap layer or implanting fluorine, increases as the agent comes closer to the $\mathrm{AlGaN} / \mathrm{GaN}$ interface. Unfortunately, when introducing a cap layer or recessing the gate, coming closer to the interface means decreasing the barrier thickness, which strongly affects the density of the 2DEG. In the case of fluorine implantation, getting closer will increase the probability of fluorine ions getting into the channel and hence degrade the mobility of the 2DEG [16].

\section{SIMULATION STRATEGY}

In this work, a new normally-off MIS-HEMT is studied. Our proposed method is based on the implantation of fluorine below the channel layer. Although this technique has been previously studied with the HEMT [17], its potential in increasing the threshold voltage was limited by the voltage at which the Schottky gate opens. According to the use of the insulator below the gate, the limitations of the technique is studied. Moreover, the effect of the thickness of the insulator on the threshold voltage, and that for various fluorine concentrations, is pulled out.

To perform this study, ATLAS, a physically-based TCAD simulation tool from Silvaco is used. Physical models used in the simulation include Shockley-Read Hall recombination, Fermi-Dirac statistics and field-dependent mobility [18]. The simulator was calibrated using a normally-on HEMT device as shown in figure 1.

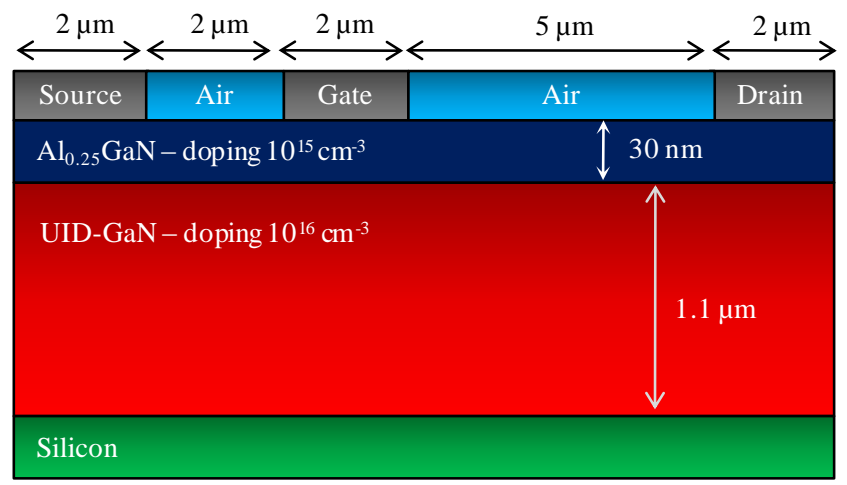

Fig. 1. Cross section of the normally-on HEMT used to calibrate the simulator.

To match the simulated threshold voltage, transconductance and off-state current with the ones experimentally measured (figure 2), the energy and the concentration of the acceptor traps, as well as the density of the 
two dimensional electron gas, were tuned. Some of the parameters used during the simulation are shown in Table 1.

TABLE I. PARAMETERS USED IN THE SIMULATION

\begin{tabular}{|c|c|}
\hline Parameter & Value \\
\hline Band offset $[\mathbf{e V}]$ & $0.7\left(\mathrm{E}_{\mathrm{g}}\left(\mathrm{Al}_{x} \mathrm{GaN}\right)-\mathrm{E}_{\mathrm{g}}(\mathrm{GaN})\right)$ \\
$\mathbf{x}$-mole fraction of Aluminum in AIGaN $" \boldsymbol{~}{ }^{\prime}$ & $0.25-0.18$ \\
Band Gap of $\mathbf{A l}_{x} \mathbf{G a N}[\mathbf{e V}]$ & $6.2 x+3.4(1-x)-1.3 x(1-x)$ \\
Dielectric Constant of $\mathbf{A l}_{x} \mathbf{G a N}[\mathbf{e V}]$ & $9.5-0.5 x$ \\
Interfacial charge density $\left[\mathbf{c m}{ }^{2}\right]$ & $\mathbf{k}\left(\mathrm{P}_{\mathrm{GaN}}-\mathrm{P}_{\mathrm{Alx} x \mathrm{GaN}}\right) / \mathrm{q}$ \\
Fitting parameter $\mathbf{k}$ & 0.61 \\
\hline
\end{tabular}

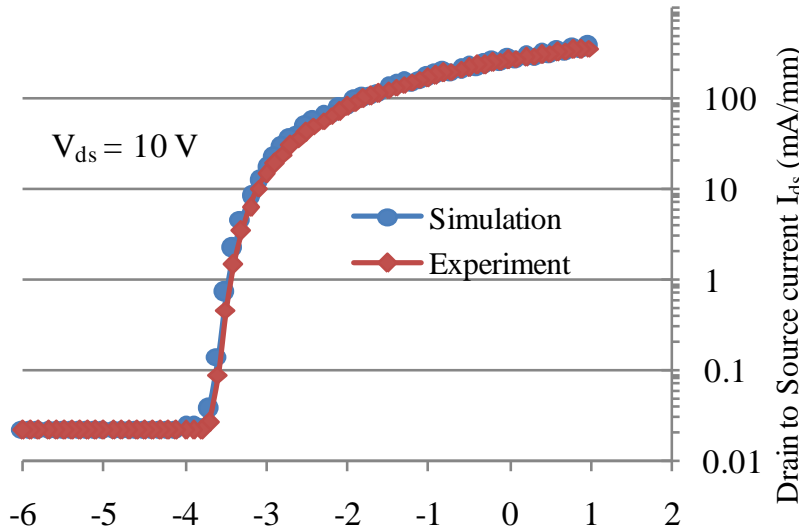

Gate to Source voltage $\mathrm{V}_{\mathrm{gs}}(\mathrm{V})$

Fig. 2. Comparison of the experimental and simulated $I_{d s}\left(V_{g s}\right)$ transfer characteristics of the conventional normally-on HEMT: fitting the simulated threshold voltage, transconductance and off-state current to the ones experimentally measured.

The studied structure is shown in figure 3. The insulator used is $\mathrm{Si}_{3} \mathrm{~N}_{4}$, with a relative permittivity of 7.5. The distance between the $\mathrm{AlGaN} / \mathrm{GaN}$ interface and the implanted fluorine ions is equal to $10 \mathrm{~nm}$. The thickness and doping of the $\mathrm{AlGaN}$ and GaN layers are taken the same as the normally-on HEMT used for calibration. All the device parameters remain constant throughout the simulation. However, the concentration of the implanted fluorine ions " $F_{\text {imp }}$ " and the thickness $" \mathrm{~d}_{\text {ins }}$ " of the insulator will be varied to analyse their effects on the threshold voltage.

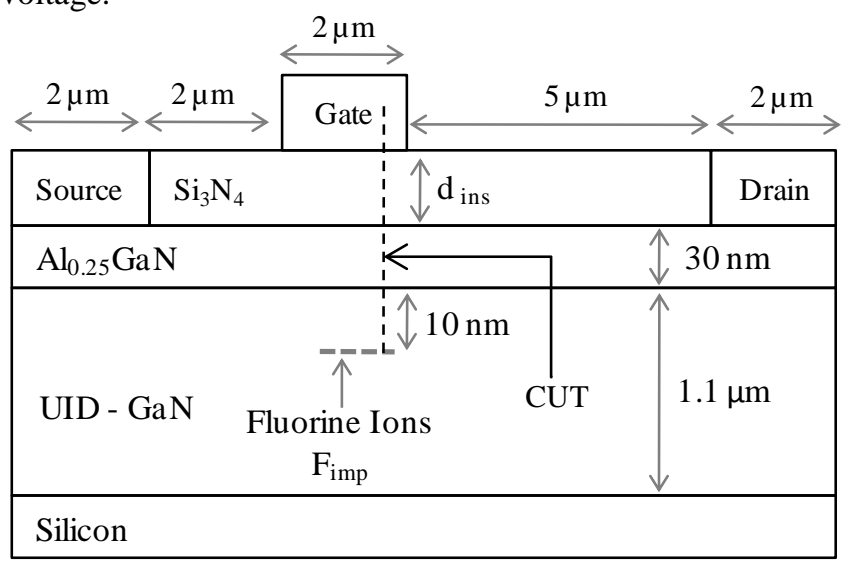

Fig. 3. Cross section of the studied MIS-HEMT. $F_{\text {imp }}$ and $d_{\text {ins }}$ were varied during the simulation.

\section{RESULTS AND DISCUSSION}

Although the aim of fluorine implantation is to achieve normally-off operation, it also can be used to reduce the offstate current of a normally-on MIS-HEMT. Figure 4 shows the transfer characteristics $\mathrm{I}_{\mathrm{ds}}\left(\mathrm{V}_{\mathrm{gs}}\right)$ for a MIS-HEMT with fluorine implanted below the channel at various concentrations. In the following simulations, the thickness $d_{\text {ins }}$ is equal to $10 \mathrm{~nm}$. It can be seen that, with increasing the fluorine concentration, the threshold voltage increases and reaches positive values making the MIS-HEMT normally-off. Moreover, implanting fluorine ions helps to reduce the off-state current. It is worth noting that further increase in the fluorine concentration $\left(\mathrm{F}_{\text {imp }}>4 \times 10^{-2}\right.$ $\mathrm{cm}^{-2}$ ) will not cause further reduction in the off-state current. The lowest off-state current reached is equal to that of the normally-on HEMT (the one used for calibration).

Fluorine concentration $\left(\mathrm{cm}^{-2}\right)$

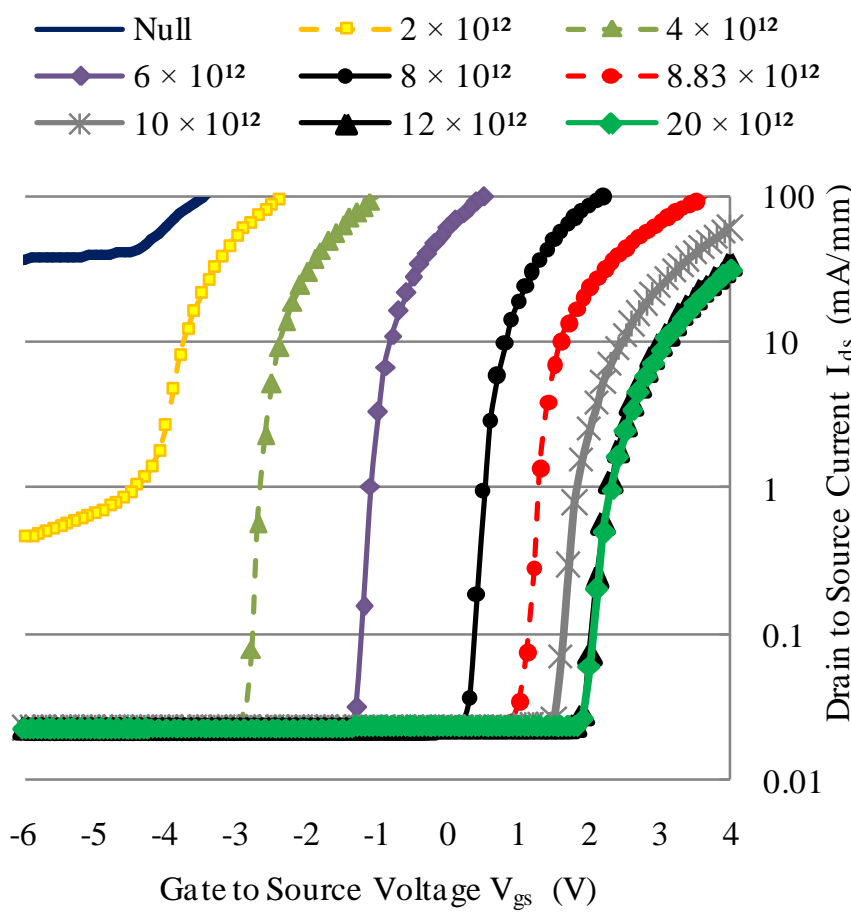

Fig. 4. $\mathrm{I}_{\mathrm{ds}}\left(\mathrm{V}_{\mathrm{gs}}\right)$ transfer characteristics of the MIS-HEMT at various fluorine concentrations for $\mathrm{d}_{\text {ins }}=10 \mathrm{~nm}$.

In figure 5 , the variations of the threshold voltage with $\mathrm{F}_{\mathrm{imp}}$, at $\mathrm{d}_{\text {ins }}=10,20$ and $40 \mathrm{~nm}$, is illustrated. It is clear that the threshold voltage increases with increasing the fluorine concentration. However, a point is reached $\left(\mathrm{F}_{\mathrm{imp}}=\mathrm{F}_{\text {optimum }}=\right.$ $\left.12 \times 10^{12} \mathrm{~cm}^{-2}\right)$, where a further increase in the concentration will no longer affect the threshold voltage. To explain this limitation, the band diagram along the CUT of figure 3 , is shown in figure 6. Introducing fluorine ions in a semiconductor will shift the Fermi level towards the valence band, thus increasing the gap between the conduction band and the Fermi level. However, since at equilibrium the Fermi level is constant, the increase in the gap will manifest itself through uplifting the conduction band. The uplift of the conduction band due to fluorine implantation will elevate the triangular well at the $\mathrm{AlGaN} / \mathrm{GaN}$ interface. It is worth noting that the elevation of the triangular well, with respect to the Fermi level, 
causes the shift in the threshold voltage. Nonetheless, the gap between the Fermi level and the conduction band cannot surpass the bandgap of the material in which fluorine is implanted, which is $\mathrm{GaN}$ in our case.

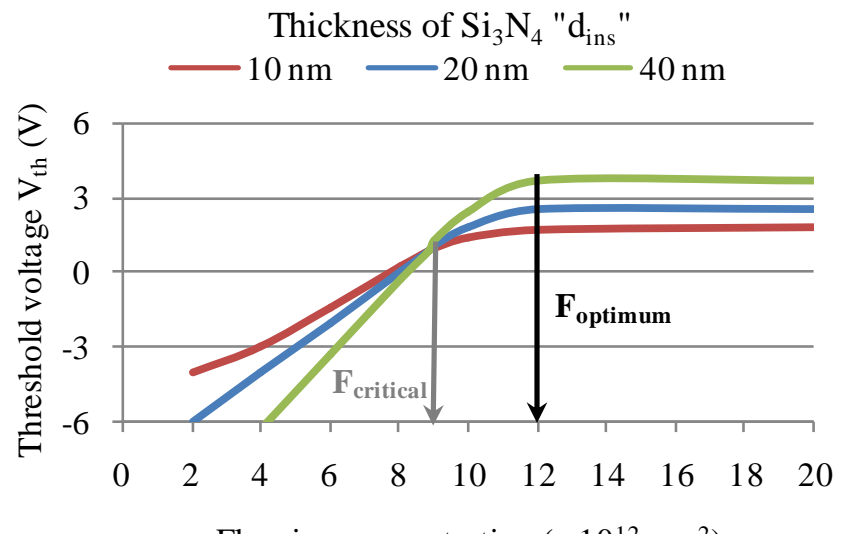

Fluorine concentration $\left(\times 10^{12} \mathrm{~cm}^{-2}\right)$

Fig. 5. Variations of the threshold voltage with the fluorine concentration at various thicknesses of the insulator.

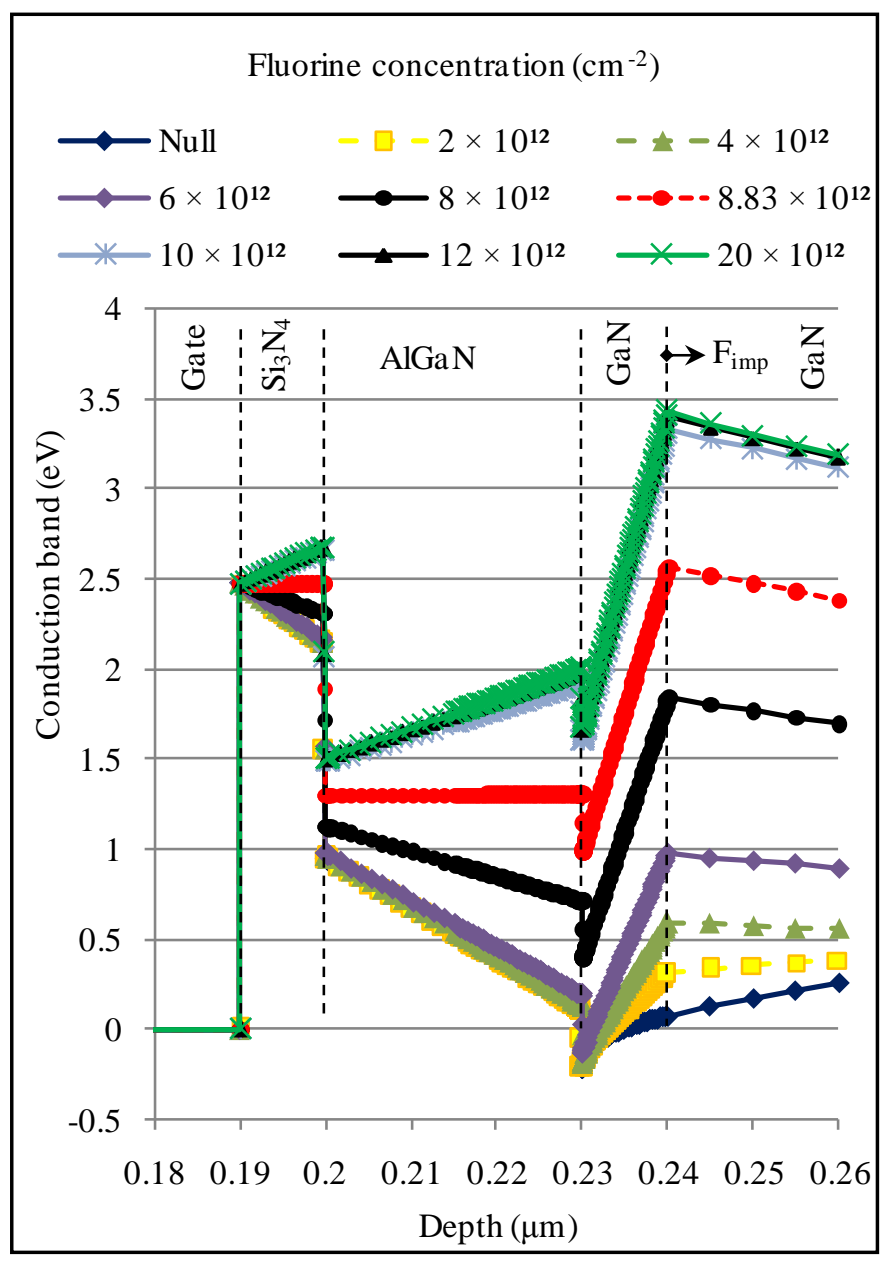

Fig. 6. Band diagrams of MIS-HEMT at various fluorine concentrations. $\mathrm{d}_{\text {ins }}=10 \mathrm{~nm}$.
Therefore, the threshold voltage will keep on increasing as long as the gap between the conduction band and the Fermi level is less than the bandgap. Once the gaps are equal, fluorine ions will be incapable to increase the gap and hence lifting further the triangular well, which causes the increase in the threshold voltage.

It should be noted from figure 5, that all the curves corresponding to various $\mathrm{d}_{\mathrm{ins}}$, intersect at a common point. The fluorine concentration associated with this point is named $\mathrm{F}_{\text {critical }}$. To further explore the effect of the thickness of the insulator on the threshold voltage, $d_{\text {ins }}$ is varied from $10 \mathrm{~nm}$ to $320 \mathrm{~nm}$. The variation of the threshold voltage with the thickness of the insulator at various fluorine concentrations is shown in figure 7 . It is clear that the variation of $V_{\text {th }}$ with $d_{\text {ins }}$ strongly depends on $\mathrm{F}_{\text {imp. }}$. The concentration of fluorine $\mathrm{F}_{\text {critical }}$, at which the threshold voltage is not affected by the thickness of the insulator, is equal to $8.83 \times 10^{-12} \mathrm{~cm}^{-2}$. Two cases are pulled out: for $F_{\text {imp }}<F_{\text {critical }}$, the threshold voltage decreases with increasing $\mathrm{d}_{\text {ins }}$, and for $\mathrm{F}_{\text {imp }}>\mathrm{F}_{\text {critical }}$, the threshold voltage increases with increasing $\mathrm{d}_{\text {ins }}$. The different variations in the threshold voltage with respect to the thickness of the insulator is directly related to the direction of the y-component of the electric field " $\mathrm{E}_{\mathrm{y}}$ " in the $\mathrm{AlGaN}$ layer, above the region where fluorine ions are implanted. When $\mathrm{E}_{\mathrm{y}}=0$, the threshold voltage will be unaffected by the thickness of the insulator. If $\mathrm{E}_{\mathrm{y}}$ is pointing towards the gate electrode, the threshold voltage will decrease with increasing the thickness of the insulator, and vice versa: if $\mathrm{E}_{\mathrm{y}}$ points towards the substrate the threshold voltage increases with increasing the thickness of the insulator. The direction of $E_{y}$ can be extracted from the profile of the conduction band shown in figure $6\left(\mathrm{Ey} \propto-\mathrm{dE}_{\mathrm{c}} / \mathrm{dy} ; \mathrm{y}=\mathrm{depth}\right)$. In our simulation, the positive y-direction points towards the substrate. When $\mathrm{F}_{\text {imp }}=\mathrm{F}_{\text {critical }}=8.83 \times 10^{12} \mathrm{~cm}^{-2}$, the conduction band is constant and hence $\mathrm{E}_{\mathrm{y}}=0$. At $\mathrm{F}_{\mathrm{imp}}=8 \times 10^{12} \mathrm{~cm}^{-2}<$ $F_{\text {critical }}$ the conduction band is decreasing $\Rightarrow \mathrm{E}_{\mathrm{y}}>0$ and at $\mathrm{F}_{\text {imp }}=1 \times 10^{13} \mathrm{~cm}^{-2}>\mathrm{F}_{\text {critical }}$ the conduction band is increasing $\Rightarrow \mathrm{E}_{\mathrm{y}}<0$.

Fluorine concentration $\left(\mathrm{cm}^{-2}\right)$

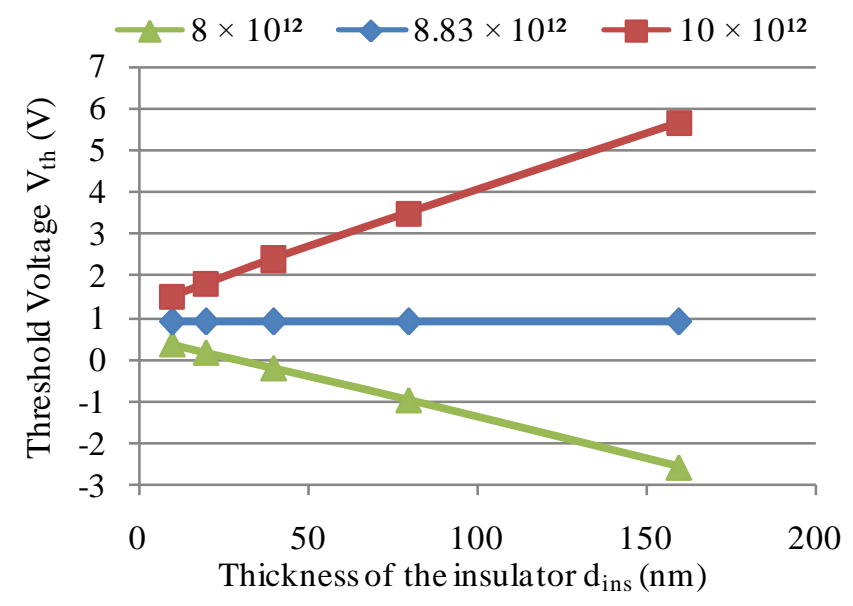

Fig. 7. Variations of the threshold voltage with the thickness of the insulator at various fluorine concentrations. 


\section{CONCLUSION}

A sensitivity analysis is carried out for the normally-off MIS-HEMT with fluorine implanted below the channel. The limitation in the capability of fluorine implantation to increase the threshold voltage is addressed and explained. Moreover, the effect of the thickness of the insulator on the threshold voltage at various fluorine concentrations is studied. Simulation results have confirmed the ability of fluorine ions to increase the threshold voltage when implanted below the channel. However, a point is reached where further increase in the fluorine concentration will not affect the threshold voltage. This is due to the fact that the gap between the Fermi level and the conduction band becomes equal to the bandgap of the material in which fluorine is implanted. Moreover, the effect of the thickness of the insulator on the threshold voltage strongly depends on the fluorine concentration implanted. An increase in the thickness of the insulator will increase the threshold voltage if the concentration implanted is above $\mathrm{F}_{\text {critical }}$ (in our simulation, $F_{\text {critical }}=8.83 \times 10^{12} \mathrm{~cm}^{-2}$ ), decrease it if the concentration implanted is below $F_{\text {critical }}$ and the threshold voltage is unaffected if the concentration implanted is equal to $\mathrm{F}_{\text {critical. }}$.

\section{ACKNOWLEDGMENT}

This work was funded by the Laboratory for Analysis and Architecture of Systems (LAAS - CNRS/France) and by GET/EDST/UL- AZM \& SAADA association.

\section{REFERENCES}

[1] U. K. Mishra, P. Parikh, and Y.-F. Wu, "AlGaN/GaN HEMTs-an overview of device operation and applications," Proc. IEEE, vol. 90, no. 6, pp. 1022-1031, 2002.

[2] H. Kambayashi, Y. Satoh, T. Kokawa, N. Ikeda, T. Nomura, and S. Kato, "High field-effect mobility normally-off AlGaN/GaN hybrid MOS-HFET on Si substrate by selective area growth technique," SolidState Electron., vol. 56, no. 1, pp. 163-167, Feb. 2011.

[3] S. D. Burnham, K. Boutros, P. Hashimoto, C. Butler, D. W. S. Wong, $\mathrm{M}$. Hu, and M. Micovic, "Gate-recessed normally-off GaN-on- Si HEMT using a new $\mathrm{O}_{2}-\mathrm{BCl}_{3}$ digital etching technique," Phys. Status Solidi C, vol. 7, no. 7-8, pp. 2010-2012, 2010.

[4] H. Chen, M. Wang, and K. J. Chen, "Self-aligned enhancement-mode AlGaN/GaN HEMTs using $25 \mathrm{keV}$ fluorine ion implantation," in Device Research Conference (DRC), 2010, 2010, pp. 137-138.

[5] X. Hu, G. Simin, J. Yang, M. A. Khan, R. Gaska, and M. S. Shur, "Enhancement mode AlGaN/GaN HFET with selectively grown pn junction gate," Electron. Lett., vol. 36, no. 8, pp. 753-754, 2000.
[6] Y. Ohmaki, M. Tanimoto, S. Akamatsu, and T. Mukai, "EnhancementMode AlGaN/AlN/GaN High Electron Mobility Transistor with Low On-State Resistance and High Breakdown Voltage," Jpn. J. Appl. Phys., vol. 45, no. No. 44, pp. L1168-L1170, Nov. 2006.

[7] M. Higashiwaki, T. Mimura, and T. Matsui, "Enhancement-Mode AlN/GaN HFETs Using Cat-CVD SiN," IEEE Trans. Electron Devices, vol. 54, no. 6, pp. 1566-1570, 2007.

[8] T. Mizutani, M. Ito, S. Kishimoto, and F. Nakamura, "AlGaN/GaN HEMTs With Thin InGaN Cap Layer for Normally Off Operation," IEEE Electron Device Lett., vol. 28, no. 7, pp. 549-551, 2007.

[9] M. Kodama, M. Sugimoto, E. Hayashi, N. Soejirria, O. Ishiguro, M Kanechika, K. Itoh, H. Ueda, T. Uesugi, and T. Kachi, "GaN-Based Trench Gate Metal Oxide Semiconductor Field-Effect Transistor Fabricated with Novel Wet Etching," Appl. Phys. Express, vol. 1, no. 2.

[10] W. Huang, Z. Li, T. P. Chow, Y. Niiyama, T. Nomura, and S. Yoshida, "Enhancement-mode gan hybrid MOS-HEMTs with Ron,sp of 20 mohm- $\mathrm{cm}^{2}$," in 20th International Symposium on Power Semiconductor Devices and IC's, 2008. ISPSD '08, 2008, pp. 295-298.

[11] Z. Tang, Q. Jiang, Y. Lu, S. Huang, S. Yang, X. Tang, and K. J. Chen, "600-V Normally Off SiNx /AlGaN/GaN MIS-HEMT With Large Gate Swing and Low Current Collapse," IEEE Electron Device Lett., vol. 34, no. 11 , pp. 1373-1375, 2013.

[12] C. Liu, E. F. Chor, and L. S. Tan, "Enhanced device performance of AlGaN/GaN HEMTs using $\mathrm{HfO}_{2}$ high-k dielectric for surface passivation and gate oxide," Semicond. Sci. Technol., vol. 22, no. 5, p. 522, May 2007.

[13] C.-T. Chang, T.-H. Hsu, E. Y. Chang, Y.-C. Chen, H.-D. Trinh, and K J. Chen, "Normally-off operation AlGaN/GaN MOS-HEMT with high threshold voltage," Electron. Lett., vol. 46, no. 18, pp. 1280-1281, 2010 .

[14] B. Zhang, S. Tan, J. Xu, Z. Dong, G. Yu, Y. Cai, L. Xue, H. Chen, K. Hou, D. Zhao, Y. Wang, S. Liu, and K. J. Chen, "5.3A/400V normallyoff AlGaN/GaN-on-Si MOS-HEMT with high threshold voltage and large gate swing," Electron. Lett., vol. 49, no. 3, pp. 221-222, Jan. 2013.

[15] M. Kanamura, T. Ohki, T. Kikkawa, K. Imanishi, T. Imada, A. Yamada, and N. Hara, "Enhancement-Mode GaN MIS-HEMTs With nGaN/i-AlN/n-GaN Triple Cap Layer and High- Gate Dielectrics," IEEE Electron Device Lett., vol. 31, no. 3, pp. 189-191, 2010.

[16] L. Yuan, M. J. Wang, and K. J. Chen, "Fluorine plasma ion implantation in AlGaN/GaN heterostructures: A molecular dynamics simulation study," Appl. Phys. Lett., vol. 92, no. 10, p. 102109, Mar. 2008.

[17] S. Hamady, F. Morancho, B. Beydoun, P. Austin, and M. Gavelle, "A new concept of enhanced-mode GaN HEMT using fluorine implantation in the GaN layer," in 2013 15th European Conference on Power Electronics and Applications (EPE), 2013, pp. 1-6.

[18] ATLAS User's Manual DEVICE SIMULATION SOFTWARE, SILVACO, Inc., Santa Clara, CA, 2011, pp. 330-331. 